\title{
Educação Física, gênero e escola: uma análise da produção acadêmica
}

\author{
Alexandre Jackson Chan-Vianna* \\ Diego Luz Moura ${ }^{* *}$ \\ Ludmila Mourão $o^{* * *}$
}

Resumo: O objetivo do estudo foi analisar as argumentações que sustentam a afirmação de discriminação das meninas nas aulas de educação física, na produção das pesquisas dos programas sensu stricto em educação física do banco de teses da CAPES. Cinco estudos foram identificados e analisados a partir das categorias analíticas: propostas das pesquisas; discriminação nas aulas de educação física; a esportivização e o sexismo, e o conceito de sexismo. As pesquisas, de um lado, denunciam o sistema escolar por reforçar o sexismo mas, por outro, apontam que gênero não é o único fator de inclusão e exclusão.

Palavras-chave: Educação física. Identidade de gênero. Preconceito. Dissertações Acadêmicas como Assunto.

\section{INTRODUÇÃO}

Uma das principais tarefas dos educadores é construir um modelo pedagógico que torne $\mathrm{o}$ acesso às atividades escolares mais democráticos. O desafio pedagógico é refletir sobre as diferenças e promover a equidade, sem estigmatizar os envolvidos. A ciência é fundamental nesse processo. Muitos discursos e ações adotadas nas escolas têm como pano de fundo as prescrições formuladas teoricamente e difundidas através de publicações e debates acadêmicos originados pela produção científica.

\footnotetext{
* Doutorando no Programa de Pós-Graduação em Educação Física da Universidade Gama Filho. Bolsista da CAPES. Rio de Janeiro, RJ, Brasil. E-mail: a.jackson@uol.com.br.

" Mestre em Educação Física. Docente do Centro Universitário da Cidade (UniverCidade) e da Secretaria Estadual de Educação do Rio de Janeiro. Rio de Janeiro, RJ, Brasil. E-mail: lightdiego@yahoo.com.br.

*** Professora do Programa de Pós-Graduação em Educação Física da Universidade Gama Filho. Rio de Janeiro, RJ, Brasil. E-mail: ludmila.mourao@terra.com.br.
} 
As pesquisas no campo da educação e da educação física escolar (MOURA; MOURÃO, 2006) sinalizam, de maneira intensa e constante, para reflexões sobre diversas categorias de desigualdades. Destacamos as que se voltaram para as questões de gênero (ABREU, 1990; OLIVEIRA, 1996; DURAN, 1999; DUARTE, 2003; PEREIRA, 2004), estabelecendo impacto significativo na produção do campo. Essas pesquisadoras procuraram discutir sobre a diferença de oportunidades entre meninos e meninas e anunciaram que as aulas de educação física possibilitavam a produção de desigualdades de gênero. Todo este movimento foi responsável por consolidar o entendimento de que a instituição escolar poderia, veladamente, reproduzir estereótipos discriminatórios que existiam na sociedade.

Tomando como referência a visibilidade das pesquisas de gênero na educação física escolar, direcionamos nossa análise para compreender a elaboração das perguntas de partida, lançando o olhar para a construção dos principais argumentos que consolidaram as conclusões das pesquisas. Nossa intenção é, sobretudo, proporcionar continuidade nas discussões de gênero produzidas na educação física brasileira.

\section{Metodologia}

Realizamos um levantamento das teses e dissertações produzidas nos programas de pós-graduação sensu stricto em educação física no período de 1990 a 2005. ${ }^{1}$ Coletamos as pesquisas através do banco de teses do Núcleo Brasileiro de Dissertações e Teses em Educação Física e Educação Especial (NUTESES) e da Coordenação de Aperfeiçoamento de Pessoal de Nível Superior (CAPES). Combinamos as palavras gênero e educação física escolar; gênero, sexismo e escola, encontrando sete estudos. Estes utilizavam o termo gênero no sentido de diferenças sócio-históricas entre homens e mulheres. O fator de inclusão foi compulsar os estudos na íntegra. Tivemos acesso a cinco deles e priorizamos identificar e descrever como as autoras ${ }^{2}$ sustentam suas argumentações. Reportamos-nos

\footnotetext{
1 O recorte do período deu-se pela identificação das primeiras pesquisas, 1990, e pelo levantamento ter ocorrido no ano de 2006.

${ }^{2}$ Todas as pesquisas analisadas foram produzidas por mulheres.
} 
a Booth, Colomb e Williams (2000), que indicam que um bom argumento compreende: a afirmação, a evidência e a ressalva. Uma afirmação é aquilo que queremos que os outros acreditem; as evidências são as razões pelas quais eles devem acreditar; a ressalva é utilizada para deixar as afirmações e as evidências mais precisas, estipulando as condições em que o argumento se sustenta.

Este trabalho apresenta limitações que se justificam. Em primeiro lugar, optamos por analisar apenas a produção dos programas de pós-graduação sensu stricto em educação física, mesmo reconhecendo a extensa produção em programas de áreas afins. A opção justifica-se, antes de tudo, pela viabilidade de leitura completa das obras, garantindo respeito à produção e à compreensão dos argumentos. Além disso, privilegiamos a produção onde se encontram, além de alunos(as), professores(as)-orientadores(as) com formação em educação física. Assim, focalizamos o debate na produção científica e na intervenção pedagógica de nossa área, no intuito de ampliá-lo.

Em segundo lugar, utilizamos as bases de dados do NUTESES e da CAPES. Nelas estão as teses e dissertações produzidas na pósgraduação brasileira. Consideramos improvável que algum estudo publicado no período de 1990 a 2005 esteja fora desse acesso, mas não existiu essa garantia. Sabemos que o debate de gênero é dinâmico e intenso, sendo assim, várias obras têm surgido e apresentado novos rumos. Entretanto, o recorte dessa revisão é relevante e registra um período seminal da temática, com apenas um estudo de doutorado, cumprindo nosso propósito de contribuir para os debates da produção futura.

\section{Discussão e RESUltados}

Quatro categorias foram utilizadas para análise das pesquisas: a) as propostas das pesquisas; b) discriminação e as aulas de educação física; c) a esportivização e o sexismo; d) o conceito de sexismo. 


\subsection{AS PROPOSTAS DAS PESQUISAS}

A análise das pesquisas revelou uma recorrência nas propostas de investigação, que na maioria das vezes partem do pressuposto da existência de sexismo e discriminação nas aulas de educação física e se esforçam para confirmar este pressuposto. Bachelard (2003) denomina este fenômeno de "opinião primeira" - quando crenças e valores são admitidos como realidade e, com isso, o objeto de estudo condiciona-se ao olhar do pesquisador. Esta atitude nos distancia da realidade, na medida em que preconiza legitimar a crença do pesquisador.

A pesquisa de Abreu (1990) é a mais antiga e se torna referência sobre o tema gênero e educação física escolar. Podemos dizer que é o texto fundador e, portanto, citado nas outras pesquisas. $\mathrm{O}$ estudo, baseado presumivelmente nas leituras e intervenção profissional da autora, relata sua proposta de pesquisa da seguinte forma:

Vejo que tanto na prática tecnicista quanto na prática humanista do profissional de educação física existem discriminações. Estas são disfarçadas com a simples separação das turmas em grupos feminino e masculino. Convém observar que quando falo em discriminação não é só em relação às meninas; mas também de uma atitude discriminatória a ambos os sexos, uma vez que se espera do menino atitudes pré-estabelecidas. [...] Tanto os meninos quanto as meninas irão preferir esta divisão, pois já estão impregnados de valores discriminatórios advindos de condicionantes sociais. (ABREU, 1990, p. 1314)

A autora aponta, apenas a partir de suas experiências, mas sem a sistematização de dados empíricos, para a existência de discriminação e sexismo nas aulas de educação física escolar. A divisão da turma em dois grupos, tendo como referência o sexo dos alunos, seria uma característica do processo discriminatório. Ainda na proposta, Abreu propõe como superação destes mecanismos de discriminação a utilização de turmas mistas, pois, de acordo com sua narrativa, "[...] talvez se contribuísse para uma melhor integração e ajuda mútua para o convívio social em relação às condições exis-

Movimento, Porto Alegre, v. 16, n. 02, p. 149-164, abril/junho de 2010. 
tentes e absorção dos conteúdos" (ABREU, 1990, p. 16). Verificase que desde o início já se tem a solução para os conflitos de discriminação e a resposta para suas perguntas. Abreu não apresenta evidências que possibilitem entender como diagnosticou o fenômeno da discriminação e com base em quais parâmetros construiu a proposta de aulas mistas.

Com o mesmo pressuposto, Oliveira (1996, p. 40) utiliza um tom de convocação para declarar sua posição política:

Para aqueles que reconhecem e são contrários aos valores sexistas que têm sido veiculados na Educação Física escolar, e que têm se preocupado com o progresso da área. [...] serão apresentados alguns pressupostos que norteiam este estudo e indicam a possibilidade de as turmas mistas contribuírem ou não para o processo de formação do educando.

Duarte (2003, p. 4) também evidencia uma predisposição em encontrar os resultados esperados:

Entendendo que todos estes aspectos resultam na construção de critérios de seleção entre meninos e meninas, penso que nas escolhas dos times temos a representação das relações de poder nas aulas de Educação Física. Esta seleção interioriza os critérios de dominação e perpetua uma classificação, que é intrínseca e fortalece o poder de uns - os meninos e ao mesmo tempo reafirma o fracasso de outros as meninas.

A autora parte da ideia de que o ritmo de aula e os critérios de seleção são ditados pelos padrões masculinos de desempenho nas atividades físico-esportivas. Desde o início da argumentação, declara que existe um sexismo presente nas aulas.

As propostas de qualquer pesquisa são guiadas pelas suas questões de estudo e/ou hipótese(s). Segundo Bachelard (2003, p. 18), é fundamental elaborarmos boas questões, pois "[...] todo conhecimento científico é resposta a uma pergunta". As perguntas recor- 
rentes nestas pesquisas procuram verificar se os valores conservadores estão sendo mantidos e/ou reproduzidos nas aulas de educação física (ABREU, 1990); até que ponto o fato de unir meninos e meninas nas aulas de educação física assegura atingir os objetivos afetivossociais (OLIVEIRA, 1996); como a educação física reproduz os estereótipos de gênero em suas aulas (DURAN, 1999); se as alunas sentem-se excluídas das aulas de educação física (DUARTE, 2003); quais são os estereótipos de gênero presentes nas aulas (PEREIRA, 2004). As perguntas que motivaram as pesquisas demonstram intenção de confirmar uma verdade já imaginada. Do modo que estão formuladas, as perguntas dirigem o olhar especificamente ao que se quer ver e com isso perde-se a oportunidade de refletir, de forma mais aguçada e crítica, sobre o fenômeno em questão.

As pesquisas analisadas apresentam o pressuposto do sexismo nas aulas de educação física escolar. Existe uma "opinião primeira" (BACHELARD, 2003), anterior aos dados coletados, de que há sexismo e de que as aulas reforçam este fenômeno. Assim, o esforço da pesquisa seria para identificar onde se esconde o sexismo.

Não se pretende aqui advogar a favor de uma neutralidade absoluta entre pesquisador e objeto de estudo, pois nem a disciplina mais positivista na atualidade parece admitir essa possibilidade. No entanto, Becker (1997) afirma que entre a crítica radical e a boa pesquisa a segunda sempre terá maior possibilidade de provocar mudanças sociais, pois é conhecendo melhor a realidade que se abrem caminhos para transformá-la. Um esforço fundamental a que deveríamos nos propor seria o de realizar um estranhamento ${ }^{3}$ sobre nós mesmos(as), antes do próprio objeto que estudamos.

As perguntas deveriam buscar a contradição para superar o que Bachelard chama de "instinto conservativo". É necessário que as pesquisas, tanto de gênero quanto de qualquer outro campo, sejam capazes de questionar seus pressupostos, pois só assim estaría-

\footnotetext{
${ }^{3}$ Duvidar do que nossos olhos veem; questionar o que parece normal. A antropologia urbana propõe que tratemos os eventos do nosso cotidiano assim como os primeiros investigadores viam os povos isolados. Ver, por exemplo, Velho (1994).
}

Movimento, Porto Alegre, v. 16, n. 02, p. 149-164, abril/junho de 2010. 
mos fazendo um exercício em prol de validar seus fundamentos para avançar no conhecimento. Duvidar da existência do sexismo nas aulas de educação física é um ponto de partida.

\subsection{A DISCRIMINAÇÃO E AS AULAS DE EDUCAÇÃO FÍSICA}

As pesquisas analisadas possuem como argumento principal a existência da discriminação nas aulas de educação física. Entretanto, suas análises carecem de evidências. Vejamos.

Duarte (2003), ainda na primeira página da pesquisa, antes de iniciar seu estudo, descreve uma visita que fez a uma escola e tece os seguintes comentários:

Um problema que detectei logo no início das aulas na escola investigada foi que as corporeidades produzidas e refletidas na Educação Física Escolar reproduzem o modelo de discriminação dos papéis masculinos e femininos existentes na sociedade, mantendo como referência os padrões masculinos. (DUARTE, 2003, p. 1)

Podemos perceber que a autora, ainda na primeira página de sua pesquisa e a partir de uma observação assistemática, ocasional, conclui pela existência de discriminação de gênero. De fato, observa-se que a necessidade da certeza imediata, conforme aponta Bachelard (2003), atrai nossas interpretações da realidade. Neste contexto, a autora denuncia a discriminação recaindo em uma simplificação do fenômeno complexo de discriminação, a partir da observação de uma única aula.

Oliveira (1996) e Pereira (2004), por vezes, atuam em tom de denúncia contra a escola, o(a) professor(a), o esporte e o rendimento esportivo. De modo geral, as autoras operam estas denúncias com análises macroestruturais, na medida em que indicam que a discriminação é a consequência de uma imposição da sociedade sobre o indivíduo, eliminando a possibilidade de manobra do indivíduo sobre a sociedade.

Wovimento, Porto Alegre, v. 16, n. 02, p. 147-167, abril/junho de 2010. 
Pereira (2004, p. 141), ao observar a dinâmica da escola, critica a formação de filas por sexo, ou a fila única, que, segundo a autora, privilegiam as meninas na frente. Por outro lado, justificou a formação de filas como uma solução para manter a organização e o controle das crianças. Pereira conclui "[...] que a escola favorece os agrupamentos por sexo, reforçando-os através de atitudes, palavras e/ou rituais que vão incutindo nas crianças a idéia de separação".

O esforço em perceber a discriminação de gênero em qualquer fenômeno social pode deixar nebuloso o olhar do pesquisador. Nas pesquisas analisadas, a proposta de perceber a discriminação de gênero nas aulas de educação física se transformou em uma camisa de força que obscureceu mais do que iluminou o debate.

O avanço do conhecimento científico tem como um de seus objetivos realizar generalizações que possam explicar melhor determinados fenômenos da sociedade. Entretanto, as generalizações não podem ser confundidas com "doutrinas gerais" (BACHELARD, 2003). Enquanto as generalizações devem ser utilizadas quando houver evidências empíricas suficientes para levantar hipóteses gerais, as doutrinas gerais são apropriações que se tornam posições teóricas e políticas do pesquisador sem questionamentos mais apurados. Todos os pesquisadores, decerto, possuem maior afinidade com alguns pressupostos teóricos; todavia, os pressupostos teóricos devem nos ajudar a fornecer olhares sobre um fenômeno, não procurar brechas para impor uma afirmação.

\subsection{AESPORTIVIZAÇÃO E O SEXISMO}

Nas pesquisas analisadas, existe um conhecimento estabelecido e anunciado que aponta para os esportes e a "esportivização"4 como uma prática exclusivamente masculina, que contribui para a discriminação de gênero e o sexismo nas aulas de educação física. Segundo Duarte (2003, p. 3), “[...] os conteúdos preferidos são os

\footnotetext{
${ }^{4}$ Nas pesquisas analisadas, entende-se esportivização como uma tendência ao exclusivo ensino dos esportes nas aulas de educação física.
}

Movimento, Porto Alegre, v. 16, n. 02, p. 149-164, abril/junho de 2010. 
esportes, e nunca a dança e a ginástica, fazendo com que as meninas aceitem a disciplina educação física como um espaço de treino, e não de aprendizagem". Pereira (2004, p. 93) afirma que "A habilidade corporal nos esportes, sobretudo em nossa cultura, ainda é tida como coisa de homem". Duran (1999) indica a esportivização como a maior responsável pela atribuição destes estereótipos:

Esta esportivização da educação física contribui para reforçar estereótipos e perpetuar características que erroneamente têm sido vinculadas a cada sexo, excluindo a mulher de sua prática e ocasionando-lhe desmotivação para realizar atividades físicas. (DURAN, 1999, p. 36)

Ao converter o esporte no conteúdo principal da educação física, faz-se com que esta disciplina seja discriminatória e sexista, já que o esporte tem-se caracterizado como uma atividade própria dos homens e um meio para reforçar sua "virilidade". (DURAN, 1999, p. 88)

Podemos perceber que estes argumentos estão imersos em generalizações, faltam delimitações que nos ajudem a entender a relação entre esportivização e discriminação. As afirmações perdem força, por exemplo, quando se pensa em outros esportes, como a ginástica rítmica.

Todas as pesquisas analisadas afirmam que uma das causas da discriminação nas aulas de educação física é a esportivização. Não encontramos argumentos que sustentem o gênero como a principal categoria de exclusão das meninas nas atividades; por outro lado, existe uma série de relatos que salientam que disponibilidade e habilidades para a prática esportiva são preponderantes para a inclusão das meninas nas aulas. $\mathrm{O}$ ensino do esporte é identificado como um fenômeno estático, que não pode sofrer apropriações.

O relato de Pereira (2004, p. 12) demonstra a evidência do desempenho e da iniciativa como fatores significativos na participação feminina nas atividades esportivas:

Durante uma aula de futebol numa quadra de areia, uma aluna da $2^{\text {a }}$ Série do Ensino Fundamental dis- 
se-me que não sabia jogar futebol. Perguntei: por quê? E a resposta foi que, no condomínio em que ela morava, os meninos não deixavam as meninas jogarem futebol, pois elas atrapalhavam a brincadeira por causa da falta de habilidade. Sugeri então que se arriscassem a ocupar o espaço de jogo deles, questionassem e insistissem até que eles dessem uma oportunidade para elas participarem do jogo. Na semana seguinte, ao voltar para a aula de Educação Física, a menina disse que minha sugestão havia dado certo e que ela e as outras colegas estavam jogando futebol quase todas as noites junto com os meninos.

Nesta descrição, o único fato que impedia a participação das meninas no jogo de futebol era a falta de uma iniciativa mais contundente delas em participar das atividades. Quando a pesquisa estreita suas lente sob o espaço escolar, a autora deixa claro que gênero não é a principal categoria de exclusão.

Observei que as meninas nunca jogam futebol com eles, com exceção de uma delas que é aceita nessa atividade porque, além de saber jogar, se dispõe a participar da atividade com eles. (PEREIRA, 2004, p. 81)

$\mathrm{Na}$ quadra estava acontecendo um jogo de futebol de meninos, com a participação de uma menina. Uma aluna dessa turma disse que a jogadora sempre joga futebol porque os meninos deixam, pois ela sabe jogar e parece um homem. (PEREIRA, 2004, p. 92, grifo da autora)

As categorias de gênero e desempenho estão sempre combinadas nos relatos apresentados. Abreu (1990) afirma durante toda a argumentação a existência da discriminação de gênero. Entretanto, ao iniciar a análise, revela uma perspectiva um pouco diferente da que apontava no início da pesquisa:

Estou otimista ao perceber que é possível reverter este quadro porque os preconceitos não são fortes, na verdade, eles estão mais concentrados em relação ao andamento das aulas e desempenho técnico (habilidades esportivas e condicionamento físico). (ABREU, 1990, p. 83).

Movimento, Porto Alegre, v. 16, n. 02, p. 149-164, abril/junho de 2010. 
Em seguida, Abreu assume declaradamente que os motivos da inclusão e da exclusão de meninos e meninas nas aulas de educação física estão mais concentrados na habilidade e menos na oposição em relação ao sexo dos participantes: "[...] o fator preponderante da incompatibilidade dos sexos em aulas mistas é o desnível das habilidades" (ABREU, 1990, p. 54). Afirma que a discriminação se dá pela habilidade, pois quando as meninas demonstram competência atlética são aceitas pelos meninos. De acordo com a autora, "[...] vale lembrar que é possível reverter o quadro conservador em que se encontram as aulas de educação física, pois os preconceitos não são fortes" (ABREU, 1990, p. 154).

Este estudo de Abreu, por ser a primeira pesquisa de gênero na educação física escolar, torna-se fonte de diálogo para os neófitos, e o mais interessante é que as pesquisas seguintes apropriam-se somente da discussão inicial, ou seja, os principais dados de sua pesquisa de campo são esquecidos ou omitidos nas análises das pesquisas posteriores.

Duarte (2003) descreve que nas escolas pesquisadas existem três grupos típicos de meninas: a) as que participam; b) as que tentam participar e c) as que boicotam as aulas. Em sua pesquisa, os grupos excluídos da atividade não são identificados somente pelo sexo, mas pelo desempenho esportivo. A autora progride em relação às demais pesquisas, ao salientar que em todas as escolas investigadas existe uma recorrência dessa tipificação. Embora avance na identificação de grupos distintos de meninas e sua relação com a atividade nas aulas de educação física, perde-se na crítica denuncista do sexismo e da discriminação de gênero, em que se apoiou durante toda a pesquisa. A distinção das alunas, com suas diferentes apropriações da prática esportiva e a regularidade dos tipos em diferentes escolas, deveriam anunciar novos pontos de vista para o entendimento das diferenças existentes na educação física escolar.

Talvez, se abandonarmos temporariamente a crença de que existem barreiras para a participação de mulheres, concentrandonos nas meninas que participam das atividades consideradas de reificação do domínio masculino, poderíamos ter uma maior compreensão sobre os fatores que aproximam e afastam cada pessoa da prática esportiva. 
$\mathrm{Na}$ produção analisada, algumas posições teóricas tomam a força de revelações pedagógicas. Assim, segundo as pesquisas, as aulas separadas são sempre negativas e as aulas mistas são defendidas como o único avanço possível. Os esportes coletivos são um mal a ser combatido na educação física curricular. Nesse contexto, a aula coeducativa torna-se a estratégia necessária para a superação das relações desiguais de gênero. Somente a aula mista ou coeducativa seria capaz, através do conflito pedagogicamente organizado, de garantir a oportunidade de participação das meninas nos esportes coletivos de confronto, dominado pelos meninos. Oliveira, sobre esse ponto, afirma que

[...] é oportuno salientar que estas não são características universais e inalteráveis, e que além de existirem meninos e meninas que fogem a estes padrões de comportamento, observa-se que os meninos são bem aceitos por meninas quando se mostram gentis e amigáveis, da mesma forma que os meninos aceitam aquelas meninas que demonstram habilidade nos jogos e tarefas motoras. (OLIVEIRA, 1996, p. 44).

Mesmo verificando a existência de meninas que participam efetivamente das atividades esportivas com os meninos, Oliveira não abre mão de ratificar que a principal categoria de exclusão é o fato de serem mulheres. Na citação, podemos perceber que a autora lança a hipótese de que possa haver outras categorias de exclusão das meninas, mas durante toda a argumentação não investe nesse ponto e mantém o gênero como principal categoria de exclusão.

Além das aulas mistas, coeducativas, as pesquisas apostam na diversidade de conteúdos em detrimento do aprendizado da técnica dos esportes de domínio masculino, que é chamado nas pesquisas pelo nome de esportivização. Ninguém defenderia um manifesto contra a diversidade nos conteúdos curriculares da educação física, mas é preciso apontar que, seguindo o raciocínio argumentativo das pesquisas, esta estratégia se fundamentaria na valorização de conteúdos de domínio feminino, para oportunizar a maior participação das meninas. Essa posição parece vitimista, pois se pensarmos a educação física escolar como espaço de apropriação da cultura do 
lazer, estaríamos preparando as meninas para continuarem despreparadas para ocupar os espaços valorizados dos jogos coletivos. Em outras palavras, poderíamos indagar: se a prática dos esportes coletivos é um instrumento de poder e as mulheres estão em minoria, ${ }^{5}$ não seria mais transformador insistir no ensino dessas modalidades para todas as meninas na escola? Não seria interessante trabalhar turmas separadas, para que elas se apropriassem melhor do conteúdo que as oprime?

\subsection{O CONCEITO DE SEXISMO}

Observa-se uma lacuna nos estudos analisados sobre a discussão do conceito de sexismo. É notório que as autoras expressam esta ideia como uma prática negativa. Entretanto, só encontramos uma definição do termo em uma nota de rodapé, no trabalho de Pereira (2004), que o explica como a separação entre os sexos. Se o conceito de sexismo presente nas pesquisas refere-se exclusivamente à separação entre os sexos, diríamos que são afirmações frágeis porque não discutem o conceito com suas delimitações e ressalvas. Banheiros e provadores de roupa nos estabelecimentos públicos das nossas cidades, por exemplo, são separados por sexo, mas nem por isso denunciados como ato sexista. Por outro lado, existem movimentos ligados ao cotismo (como o direito ao vagão exclusivo nos trens e metrôs, ou o número de representantes nos partidos políticos) que têm como objetivo garantir a igualdade de condições entre homens e mulheres. Olhando para o nosso campo de conhecimento específico, a pergunta é: O que podemos pensar sobre a proliferação das academias de ginástica feminina ou dos grupos de futebol de mulheres no lazer esportivo, que preferem o espaço unissexual? Estas questões apontam para a necessidade de se refletir mais sobre o conceito de sexismo, para sua aplicação nas questões científicas e pedagógicas da educação física.

Um conceito científico, segundo Bachelard (2003, p. 76), serve para explicar uma situação, em uma dada condição, que nos forneça a capacidade de nomear um fenômeno, torná-lo eficaz para

\footnotetext{
5 Tanto de número quanto de cotas de poder na interação com os homens.
} 
avançar o conhecimento. Entretanto, o próprio autor destaca que "[...] a fecundidade de um conceito científico é proporcional a seu poder de deformação". Quando gênero e discriminação passam a explicar todas as situações da relação entre os sexos, perdem seu poder de avançar no conhecimento, como bem fizeram quando entraram no cenário científico. $O$ conceito de gênero nestas pesquisas tornou-se um conhecimento geral que tudo explica e resolve.

Refletimos com Bachelard (2003) que um conceito deveria vir junto do seu não conceito. Procurar delimitar e duvidar dos conceitos que rondam os estudos de gênero pode nos abrir o olhar para questões aparentes que não conseguimos identificar. Como entender, por exemplo, a interpretação de sexismo diante de uma realidade que mais parece negociação a partir de escolhas individuais? Por que, mesmo com fortes evidências da habilidade esportiva como categoria de exclusão e inclusão de ambos os sexos, as pesquisas insistem em apontar o fenômeno como sexismo? Por qual motivo o desvio do modelo normativo de feminino é tão aparente nos dados pesquisados, mas tão difícil de ser tratado pelas autoras?

\section{Pensando uma nova Agenda de ESTUdos Sobre GÊNERo E EDUCAÇÃo FísICA}

Sugerimos novas pesquisas sobre a relação entre gênero e habilidade esportiva. Nos termos de Magnani (2002), as pesquisas analisadas observam o fenômeno aula de educação física de fora e de longe. Ou seja, o pesquisador recebe informações de seu objeto de pesquisa apenas através da coleta de dados. Magnani sugere que o distanciamento do observador de seu objeto contribuiria para um desequilíbrio da construção de uma posição mais autônoma. A decisão de escolha das informações válidas pelo pesquisador para sua pesquisa pode tomar muitos rumos, de acordo com seus valores, ideologias e do contexto mais imediato produzido no cenário onde acontece a decisão. Fonseca (1999, p. 66), analisando esta tentativa de crítica à distância, enfatiza que, na ausência do diálogo concreto entre pesquisador e ator social, o efeito de "[...] submeter todas as falas a um mesmo paradigma de análise é facilitar a violência simbólica exercida 
pelas classes dominantes". Acreditamos que seria interessante a realização de pesquisas que procurassem entender as relações dos atores sociais de perto e de dentro, como nos sugere Magnani (2002).

Longe de generalizações ou de não alterar a crítica a uma só direção, entendemos que precisamos de uma abordagem mais de perto e de dentro dos fenômenos que nos afligem. Entender tais fenômenos de perto e de dentro significa buscar o problema da pesquisa de forma mais aberta, ampliando as possibilidades de respostas. Ao mesmo tempo, aproximar mais os sentidos de observação dos indivíduos, de suas interações cotidianas e das razões de suas ações mais objetivas. Como destaca Oliven (2002, p. 11), o estudo sobre a cultura de grupos urbanos, dadas as contradições existentes nas sociedades complexas, “[...] necessita ser radical, no sentido etimológico do termo, isto é, procurar ir à raiz dos fenômenos que estuda, sem ter receio de desafiar tabus e conhecimentos consagrados".

Considerando a complexidade do fenômeno em questão e as rápidas transformações sociais da atualidade, seria importante largar de mão a busca de comprovação de uma discriminação absoluta e procurar compreender, considerando cada instituição em particular, em que medida cada um dos indivíduos envolvidos na trama se estabelece nas relações de poder. É preciso, especificamente nos estudos de gênero, elaborar um novo conceito, diferente do proposto sexismo, que dê conta de explicar as distinções de gênero nas práticas esportivas.

\section{CONSIDERAÇõES FINAIS}

Nas pesquisas analisadas, encontramos uma tendência na argumentação. Existe uma posição inicial identificando a discriminação. As pesquisas afirmam que existe sexismo na educação física escolar e que o esporte é o principal instrumento de reforço dessa discriminação. Após a análise dos dados, as pesquisas passam a indicar que a habilidade é o fator de influência na exclusão das meninas. Entretanto, mesmo encontrando evidências de que a habilidade seja o principal motivo da exclusão, tanto para meninas quanto para meninos, as autoras não investem esforços para compreender este fenômeno. 
As autoras das pesquisas analisadas partem da proposta de encontrar a discriminação. Encontram e reforçam o argumento da generificação com poucas evidências empíricas. Recaem por diversas vezes em generalizações para argumentar em torno dos efeitos negativos do sexismo causados pelo esporte. As argumentações possuem afirmações fortes, com evidências frágeis para sustentar o gênero como categoria de exclusão. Há uma série de relatos nas pesquisas analisadas salientando que a disponibilidade e a competência na prática esportiva foram definidoras da condição de inclusão de algumas meninas e exclusão de alguns meninos. É frequente a observação de participação de mulheres nos esportes, até no futebol, mas na maioria das vezes as pesquisadoras a trataram como um dado sem significado, um desvio. Essas constatações caracterizam o olhar enviesado sobre a realidade, causado pela dificuldade de superação dos obstáculos epistemológicos. ${ }^{6}$

As pesquisas analisadas correspondem a um esforço importante de dar voz a um determinado segmento que se encontra, em alguns contextos, com menores cotas de poder. Entretanto, a pesquisa científica não pode assumir de maneira exclusiva o plano político em detrimento de seu compromisso com a análise, pois a divulgação de seus resultados tem implicações significativas na formação e intervenção pedagógica dos profissionais da educação física. A causa da equidade entre todas as pessoas deve ser colocada sempre à frente nos propósitos da intervenção pedagógica, e a pesquisa em educação física é fundamental para destacar os caminhos a seguir. Por entendermos que esse caminho é complexo e dinâmico, compactuamos com a ideia de que, quando duvidamos, provocamos debate e criamos oportunidades para além do estabelecido.

\footnotetext{
${ }^{6}$ Nos termos de Bachelard (2003).
} 


Physical Education, gender and school:
analyzing the academic prodution
Abstract: The theme of this article is the academic
production on gender and physical education in post-
graduate programs of physical education in CAPES
database. The goal is to analyze the arguments
favoring discrimination against girls in class. Five
studies have been collected and analyzed, starting
with the following analytical categories: themes of
research; discrimination in classes of physical
education; sporting and sexism and the concept of
sexism. Analysis shows that school reinforces
sexism, but gender is not the only factor of inclusion
and exclusion.
Keywords: Physical education. Gender identity.
Prejudice. Academic Dissertations as Topic.

Educacíon Física, género y éscuela: un análisis de la produccíon académica

Resumen: Este artículo analiza la producción académica sobre género y educación física escolar de los programas stricto sensu del area. El objetivo fue analizar los argumentos que sustentan la afirmación de discriminación de las niñas en las clases. Recolectamos las obras a través del banco de tesis de CAPES. Analizamos cuatro categorías: las propuestas de las pesquisas; discriminación y las clases de educación física; la deportivización el sexismo; y el concepto de sexismo. Las pesquisas denuncian el sexismo, pero apuntan que género no es el único factor de inclusión y de exclusión, lo que sugiere un análisis más de cerca en el cotidiano de las prácticas deportivas.

Palabras clave: Educación física. Identidad de género, Prejuicio. Tesis Académicas como Asunto.

\section{REFERÊNCIAS}

ABREU, N. G. Meninos pra cá, meninas pra lá. Dissertação (Mestrado em Educação Física) - Universidade Gama Filho, Rio de Janeiro, 1990.

BACHELARD, G. A formação do espírito científico. Rio de Janeiro: Contraponto, 2003

BECKER, H. Métodos de pesquisa em ciências sociais. 3. ed. São Paulo: Hucitec, 1997.

Wovimento, Porto Alegre, v. 16, n. 02, p. 147-167, abril/junho de 2010. 
Hucitec, 1997.

Métodos de pesquisa em ciências sociais. 3. ed. São Paulo:

BOOTH, W. C.; COLOMB, G. G; WILLIAMS, J. M. A arte da pesquisa. Rio de Janeiro: Martins Fontes, 2000.

DUARTE. C. P. O discurso de escolares adolescentes femininas sobre os critérios de seleção utilizados para a participação em aulas mistas de Educação Física. Dissertação (Mestrado em Educação Física) - Universidade Gama Filho, Rio de Janeiro, 2003.

DURAN. M. V. C. A aula de educação física como reprodutora de estereótipos de gênero à luz da experiência no colégio "Inen Santiago Pérez" Santa Fé / Bogotá. Dissertação (Mestrado em Educação Física) - Universidade Estadual de Campinas, Campinas, 1999.

FONSECA, C. Quando cada caso NÃO é um caso: pesquisa etnográfica e educação. Revista Brasileira de Educação, São Paulo, v. 10, p. 58-78, 1999.

MAGNANI, J. G. C. De perto e de dentro: notas para uma antropologia urbana. Revista Brasileira de Ciências Sociais, São Paulo, v. 17, n. 49, p. 11-29, 2002.

MOURA, D. L; MOURÃO, L. A Produção histórica do conhecimento sobre gênero e educação física escolar nos cursos de pós-graduação em educação e educação física. In: CONGRESSO NACIONAL DE HISTÓRIA DO ESPORTE, LAZER, EDUCAÇÃO FÍSICA E DANÇA, 10., Curitiba, 2006. Anais...Curitiba, 2006.

OLIVEIRA, G. K. Aulas de educação física para turmas mistas ou separadas por sexo? Análise comparativa de aspectos motores e sociais. Dissertação (Mestrado em Educação Física) - Universidade Estadual de Campinas, Campinas, 1996.

OLIVEN, R. G. A antropologia de grupos urbanos. 5. ed. Rio de Janeiro: Vozes, 2002.

PEREIRA, S. A. M. O sexismo nas aulas de educação física: uma análise dos desenhos infantis e dos estereótipos de gênero nos jogos e brincadeiras. Tese (Doutorado em Educação Física) - Universidade Gama Filho, Rio de Janeiro, 2004.

VELHO, G. Projeto e metamorfose: antropologia das sociedades complexas. Rio de Janeiro: Jorge Zahar, 1994

Recebido em: 17.07.2009

Aprovado em: 17.11.2009

Movimento, Porto Alegre, v. 16, n. 02, p. 149-164, abril/junho de 2010. 